Atıf için / For Citation: B. Esencan Türkaslan, M. Aktaş, S. Akar, "Fonksiyonlaştırılmış Titanyum Dioksit Nanotüp Sentezi", Süleyman Demirel Üniversitesi Fen Edebiyat Fakültesi Fen Dergisi, 15(1), 167-176, 2020.

\title{
Fonksiyonelleştirilmiş Titanyum Dioksit Nanotüp Sentezi
}

Banu ESENCAN TÜRKASLAN ${ }^{* 1}$, Melek AKTAŞ ${ }^{1}$, Sultan AKAR ${ }^{1}$

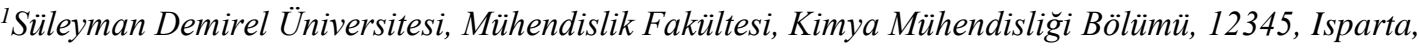 \\ Türkiye \\ *yazışllan yazar e-posta: banuturkaslan@sdu.edu.tr
}

(Alinış / Received: 27.12.2020, Kabul / Accepted: 21.05.2020, Yayımlanma / Published: 31.05.2020)

Özet: $\mathrm{TiO}_{2}$ nanotüp sentezi ile ilgili yapılan çalışmalarda belirtilen koşullarda nanotüplerin oluştuğu yönünde sonuçlar verilirken, karakterizasyon sonuçlarının nano malzemenin toz formuna ait olduğu, tübüler yapılara ait formların oluşmadığ görülmektedir. Bu çalışmada titanyum dioksit $\left(\mathrm{TiO}_{2}\right)$ tozundan hidrotermal sentez yöntemi ile $\mathrm{TiO}_{2}$ nanotüpleri elde edildi. Nanotüp sentezi için deney şartları optimize edildikten sonra elde edilen $\mathrm{TiO}_{2}$ nanotüplerin metakrilik asit ile fonksiyonlaştırma işlemi gerçekleştirildi. $\mathrm{TiO}_{2}$ tozunun yapısı, hidrotermal koşullar (sıcaklık, reaktiflerin konsantrasyonu ve hidrotermal süresi) ve sonraki yıkama işlemleri, $\mathrm{TiO}_{2}$ nanotüp yapısını (kristalografi ve morfoloji) ve fiziksel-kimyasal özelliklerini belirlemede önemli bir rol aldığı gözlendi. Sentezlenen nanotüp yapıları, Enerji Dağılım Spektrometresi (EDS), Fourier Dönüşümlü Kızılötesi Spektroskopisi (FTIR), X-Işını Kırınım Difraktometresi (XRD) ve Taramalı Elektron Mikroskobu (SEM) ile karakterize edildi.

Anahtar kelimeler: Fonksiyonelleştirilmiş Titanyum Dioksit, Nanotüp, Hidrotermal sentez

\section{Synthesis of Functionalized Titanium Dioxide Nanotube}

\begin{abstract}
Several studies releated on $\mathrm{TiO}_{2}$ nanotubes synthesis show that nanotubes do not occur under the specified conditions, while the characterization results belong to the powder form of the nanomaterials. In this study, titanium dioxide $\left(\mathrm{TiO}_{2}\right)$ nanotubes were synthesized via hydrothermal process fromcommercial $\mathrm{TiO}_{2}$ powder. After optimizing the experimental conditions for nanotube synthesis, the obtained $\mathrm{TiO}_{2}$ nanotubes were functionalized with methacrylic acid. The structure of $\mathrm{TiO}_{2}$ powder, hydrothermal conditions (temperature, concentration of reagents and hydrothermal time) and subsequent washing processes were observed to play an important role in determining the $\mathrm{TiO}_{2}$ nanotube structure (crystallography and morphology) and physical-chemical properties. The morphology of the nanotubes were characterized by Energy Dispersion Spectrometry (EDS), Fourier Transform Infrared Spectroscopy (FTIR), X-Ray Diffraction (XRD) and Scanning Electron Microscopy (SEM).
\end{abstract}

Key words: Functionalized Titanium Dioxide, Nanotube, Hydrothermal synthesis

\section{Giriş}

Küçük-boyutlu materyaller yığın haldeki malzemelerle karşılaştırıldığı zaman yeni fizikokimyasal özellikleri ile dikkat çekicidir. Nanotüp, nanotel ve nanoçubuk gibi nanoyapılar büyüklük ve şekillerine dayanan önemli özellikleri ve aynı zamanda potansiyel uygulamaları için son zamanlarda yoğun bir şekilde çalışılmaktadır [1]. Nanotüpler, bir boyutlu nano yapılar olup boşluklu iç yapılı nanofiberler olarak da 
isimlendirilmektedir. Nanomalzemeler arasında $\mathrm{TiO}_{2}$ nanotüpler, hem makro hem de mikro ölçekli kullanılabilmelerinden dolayı çok çeşitli uygulama alanlarına sahiptir [2].

$\mathrm{TiO}_{2}$ UV 1şığı ile uyarıldığı zaman fotoaktif özellik gösteren ve organik grupları parçalayabilen bu özelliği ile kendi kendini temizleyebilen yüzeylerin elde edilmesinde, havanın temizlenmesinde, fotokimyasal olarak kanser tedavisi uygulamalarında kullanılan yarı iletken bir malzemedir. Bununla birlikte; titanyum nanoparçacıkları, geliştirilmiş aşınma direnci ve mekanik dayanımları ve biyouyumlu yapısı ile biyomedikal malzeme araştırmalarında kompozit malzemelerinde takviye edici (doldurucu) olarak sıkça tercih edilmektedir [3-7]. Bu uygulamaların hepsinde farklı nano geometriye sahip nanotüp, nanotel yapıları nanopartikül kullanımına kıyasla yüzey alanını daha fazla genişlettiği için malzemenin fiziksel ve kimyasal davranışı üzerinde daha yüksek kontrol yeteneği sağladığı için tercih edilmektedir [8-10].

Doldurucu partiküllerin şekilleri, boyutları ve miktarları kompozitlerin fiziksel ve mekanik özelliklerinin ana belirleyicisidir. Nanokompozit materyallerin sentezinde matriks ve doldurucu arasında optimum bağlanmayı sağlamak için, doldurucu olarak kullanılan nanomateryallerin kümeleşme eğilimini azaltarak çözücü içerisinde dispersiyonunu arttırmak için fonksiyonelleştirme işlemi yapılmaktadır. $\mathrm{Bu}$ işlem inorganik faz ile organik matriks faz karıştırılmadan önce, doldurucu partiküllerin yüzeyine bağlayıcı ajanın uygulanması ile sağlanır. Bağlayıcı ajanlar içerisinde bifonksiyonel yapıda olan metakrilik asit $\left(\mathrm{C}_{4} \mathrm{H}_{6} \mathrm{O}_{12}\right)$ sahip olduğu karboksilik gruplar ile titanyum yapısına bağlanırken, ayrıca $\mathrm{C}=\mathrm{C}$ vinil bandlarının kopolimerizasyonu ile termal açıdan daha kararlı ve daha yüksek dayanıma sahip polimetilmetakrilat (PMMA) sentezi gerçekleştirilmektedir [11].

Nanotüp sentezlenmesinde en s1k kullanılan yöntemler sol-jel, hidrotermal, solvotermal ve elektrokimyasal yöntemlerdir [12-24]. Alkali hidrotermal yöntem, yüksek reaktivite, düşük enerji gereksinimi ve sulu çözeltinin basit kontrolü gibi birçok avantaj nedeniyle en popüler yöntemdir [25].

Hidrotermal proses parametrelerinden $\mathrm{TiO}_{2}$ tozunun özellikleri, alkali çözeltinin yapısı ve özellikleri, reaksiyon süresi ve sicaklık oluşan $\mathrm{TiO}_{2}$ nanotüp morfolojisi üzerinde belirleyici etkiye sahiptir. Hidrotermal reaksiyondan sonra yapıdaki safsızlık iyonlarını gidermek için yıkama aşaması gereklidir. Yıkama zamanları, asidin derişimi ve uygulama süresi ile etkileşim şekli nanotüp yapısını kontrol eden diğer önemli parametrelerdir [26$31]$.

$\mathrm{Bu}$ çalışmada anataz formunda $\mathrm{TiO}_{2}$ tozundan hidrotermal sentez yöntemi ile $\mathrm{TiO}_{2}$ nanotüp elde edilmiştir. Sentezin en önemli kısmı olan $\mathrm{TiO}_{2}$ tozunun tübüler formu aldı ğ asit ile etkileşimi için $\mathrm{HCl}$ ile yıkama ve 24 saat $\mathrm{HCl}$ içerisinde bekletme şeklinde iki farklı parametre çalışılmış ve sentez koşulları optimize edilmiştir. Yapılan bazı çalışmalarda belirtildiği gibi sadece asit ile yıkama yoluyla tübüler nanotüp yapılarının oluşmadığı gözlenmiştir.

Sentezi gerçekleştirilip kurutulan $\mathrm{TiO}_{2}$ nanotüplerin biyomedikal alanda kompozit malzeme uygulamalarında kullanılabilmesi için metakrilik asit ile yüzey modifikasyon işlemi uygulanarak, fonksiyonlaştırılmış $\mathrm{TiO}_{2}$ nanotüp sentezi gerçekleştirilmiştir. 


\section{Materyal ve Metot}

\subsection{Hammadde}

Bu çalışmadaki deneylerde; $13 \mathrm{~nm}$ çapında, \%99,5 saflık derecesinde ve anataz formunda $\mathrm{TiO}_{2}$ tozu (Nanografi, ODTÜ Teknokent), sodyum hidroksit (NaOH) (Isolab $\mathrm{GmbH}$, Wertheim, Almanya), 2-propanol (Sigma-Aldrich, Taufkirchen, Almanya), hidroklorik asit $(\mathrm{HCl})(\% 32 \mathrm{w} / \mathrm{w}$, Sigma-Aldrich ) ve metakrilik asit (Sigma-Aldrich, Taufkirchen, Almanya) kullanılmıştır.

\section{2. $\mathrm{TiO}_{2}$ Nanotüp Sentez Koşullarının Optimizasyonu}

İki adet 1 gr anataz kristal yapısına sahip $\mathrm{TiO}_{2}$ tozu tartıldıktan sonra her biri üzerine 10 $\mathrm{M} \mathrm{NaOH}(\% 99,5 \mathrm{w} / \mathrm{w})$ çözeltisi eklendi ve homojen hale gelmesi için 24 saat oda sıcaklığında manyetik karıştırıcıda karıştırıldı. 24 saatin sonunda karışım, otomatik su beslemeli yüksek basınç buhar sterilizatörü (Systec V-55, Wettenberg, Almanya) kullanılarak $135{ }^{\circ} \mathrm{C}$ 'de 24 saat bekletildi. Otoklavdan alınan numuneler, $\mathrm{pH}=7$ olana kadar saf su ile yıkandı. Yıkama işlemi tamamlandıktan sonra birinci numune $0.1 \mathrm{M} \mathrm{HCl}$ ile yıkanırken, ikinci numune 24 saat $0.1 \mathrm{M} \mathrm{HCl}$ içerisinde bekletildi. Tüm numuneler saf su ile $\mathrm{pH}=7$ oluncaya kadar tekrar yıkanıp filtrelendi. Tüp oluşumun gözlendiği 24 saat asitte bekleyen numune için $400^{\circ} \mathrm{C}$ ' de kalsinasyon işlemi gerçekleştirildi (Şekil 1a).

\subsection{Optimize Edilen Koşullarda Sentezlenen TiO 2 Nanotüplerin Fonksiyonlaştırılması}

İki farklı yöntemle asitle muamele edilen numune sonuçlarından $\mathrm{TiO}_{2}$ tüp formuna sahip olan 24 saat asitte bekletilen kurutulmuş haldeki $\mathrm{TiO}_{2}$ nanotüp tozlarından 0.3 gr tartılıp, üzerine $6 \mathrm{ml}$ 2-propanol asit eklenerek ultrasonik banyoda (Elmasonic S $80 \mathrm{H}$, Elma Schmidbauer GmbH, Singen, Almanya) yarım saat sonike edildi. Daha sonra karışıma $3.6 \mathrm{ml}$ metakrilik asit eklenerek, $80^{\circ} \mathrm{C}$ 'de, geri soğutucu altında 24 saat karıştırıldı. Elde edilen solüsyon $6000 \mathrm{rpm}$ 'de $15 \mathrm{dk}$ süreyle santrifüjlendi. Saf su ile yıkandı. Yıkanan fonksiyonel $\mathrm{TiO}_{2}$ nanotüpler, $80^{\circ} \mathrm{C}$ 'de vakum altında 5 saat süreyle kurutuldu (Şekil lb).

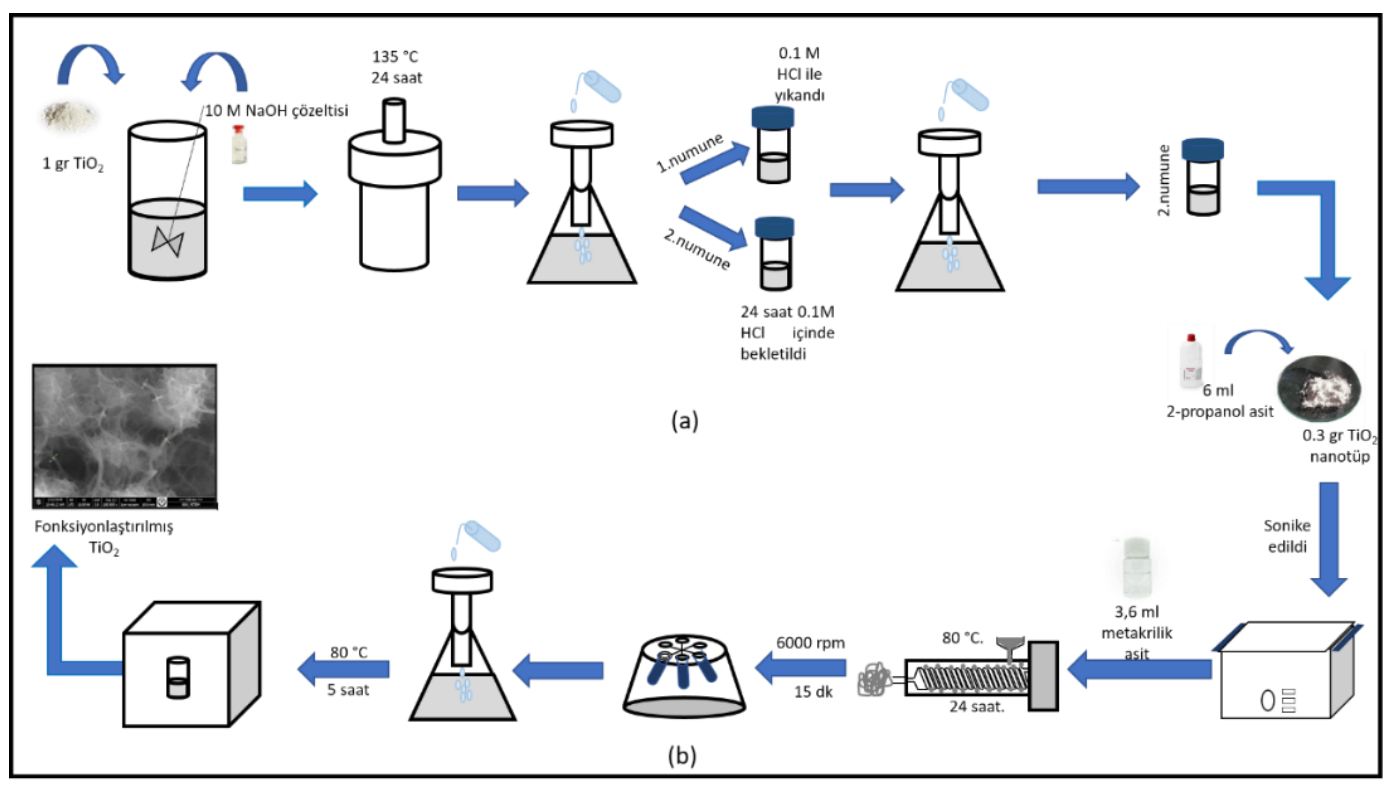

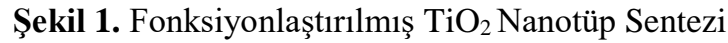




\section{Bulgular}

\section{1. $\mathrm{TiO}_{2}$ Tozunun SEM Analizi}

$\mathrm{TiO}_{2}$ tozunun ve nanotüplerin morfolojik olarak karakterizasyonu SEM (Quanta Feg 250, FEI, Hollanda) kullanılarak 12.7-13.2 mm mesafede gerçekleştirildi. $\mathrm{TiO}_{2}$ tozunun $\mathrm{X}$ 20000 büyütmede SEM görüntüsü incelendiğinde bütünüyle homojen bir şekilde dağılmadı̆̆, $\mathrm{TiO}_{2}$ tozunun kararlı olmayan yapısından kaynaklı yapıda yer yer kümeleşmiş taneciklerin varlığı gözlendi (Şekil 2) [32].

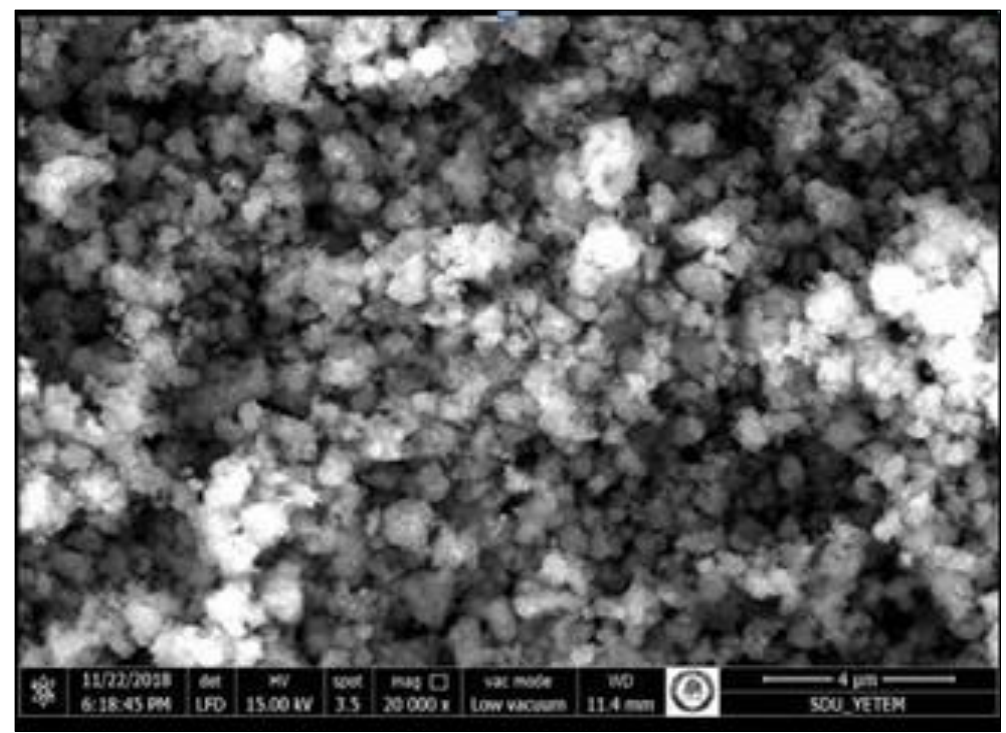

Şekil 2. $\mathrm{TiO}_{2}$ tozuna ait örneğin X 20000 büyütme SEM Görüntüsü

\subsection{Numunelerin SEM Analizleri}

Otoklavdan alındıktan sonra $\mathrm{HCl}$ ile y1kanan numuneye ait $\mathrm{SEM}$ görüntüsü incelendiğinde, tübüler yapının oluşmadığı, $\mathrm{TiO}_{2}$ tozuna benzer, kümeleşmiş tanecikli yapı görülmektedir (Şekil 3).

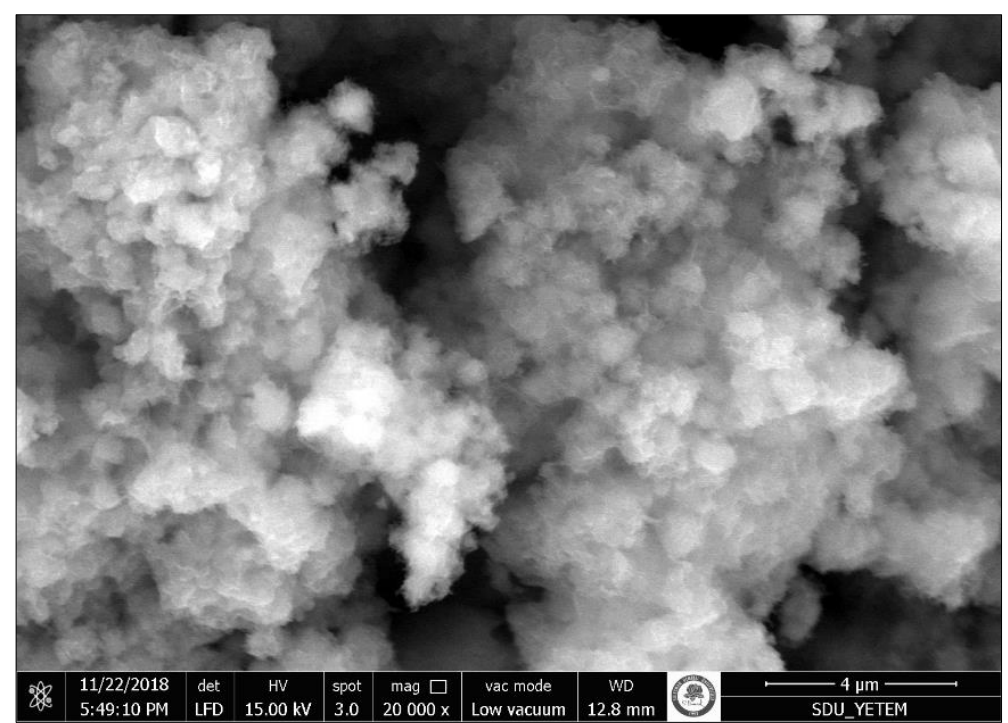

Şekil 3. $\mathrm{HCl}$ ile yıkanan $\mathrm{TiO}_{2}$ tozuna ait örneğin X 20000 büyütme SEM Görüntüsü 


\section{2. $\mathrm{TiO}_{2}$ Nanotüpüne ait SEM/EDS ve XRD Analizleri}

Hidrotermal sentez sonunda elde edilen $\mathrm{TiO}_{2}$ nanotüpüne ait SEM morfolojileri X 50.000 ve X 100.000 büyütme ölçeklerinde incelendiğinde uzun silindir şekilli, ağ şeklinde birbirine dolanmış, uzamış tübüler yapıların varlığı görülmektedir (Şekil 4 a,b). 10 farklı noktadan yapılan ölçümlerde, tübüler yapıların çapları 28.68-59.90 nm arasında ölçüldü (Şekil 4b).

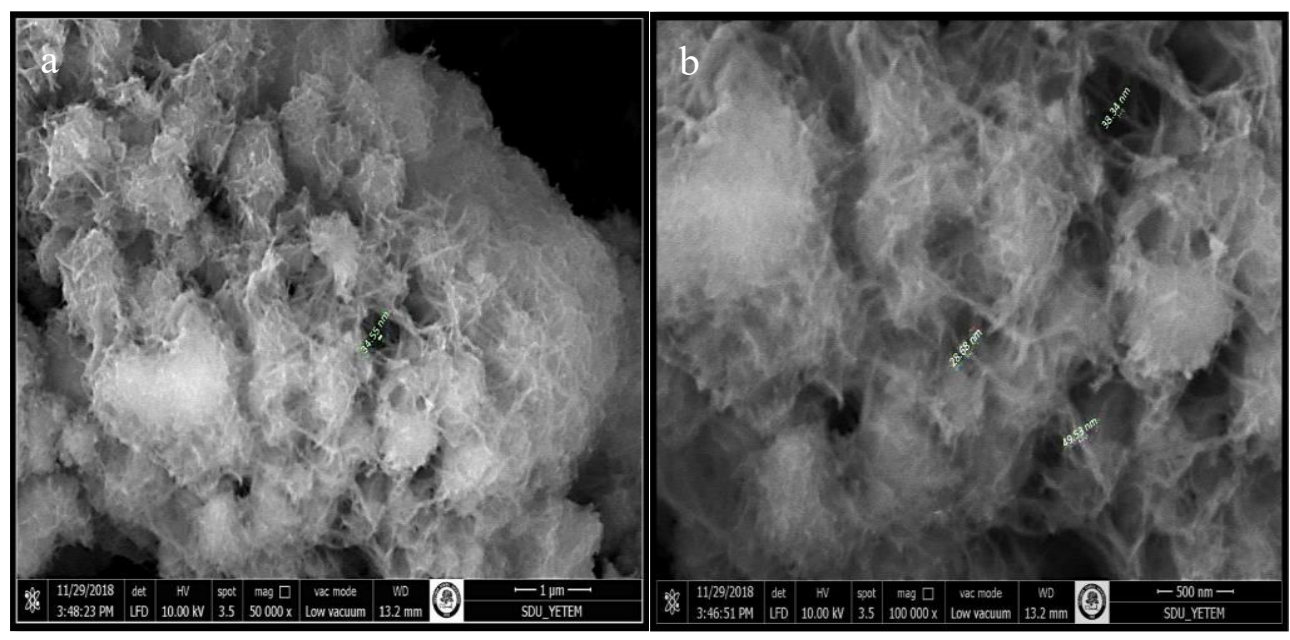

Şekil 4. $\mathrm{TiO}_{2}$ nanotübe ait örneğin SEM görüntüleri a) X 50.000 büyütme, b) X 100.000 büyütme

$\mathrm{TiO}_{2}$ nanotüplerine ait EDS analizleri incelendiğinde ise yapıda titanyum (Ti) elementinin ağırlıkça \%55.37, Oksijen (O) elementinin ise ağırlıç̧a \%44.63 oranında olduğu belirlenmiştir. Bunlara ilaveten elementel analiz sonuçlarında $\mathrm{TiO}_{2}$ yapısına tutunan sodyum iyonlarının $\mathrm{HCl}$ ile muamele ve su ile yıkama işlemi sonrasında yapıdan uzaklaştırıldığı görülmüştür (Şekil 5) [33].

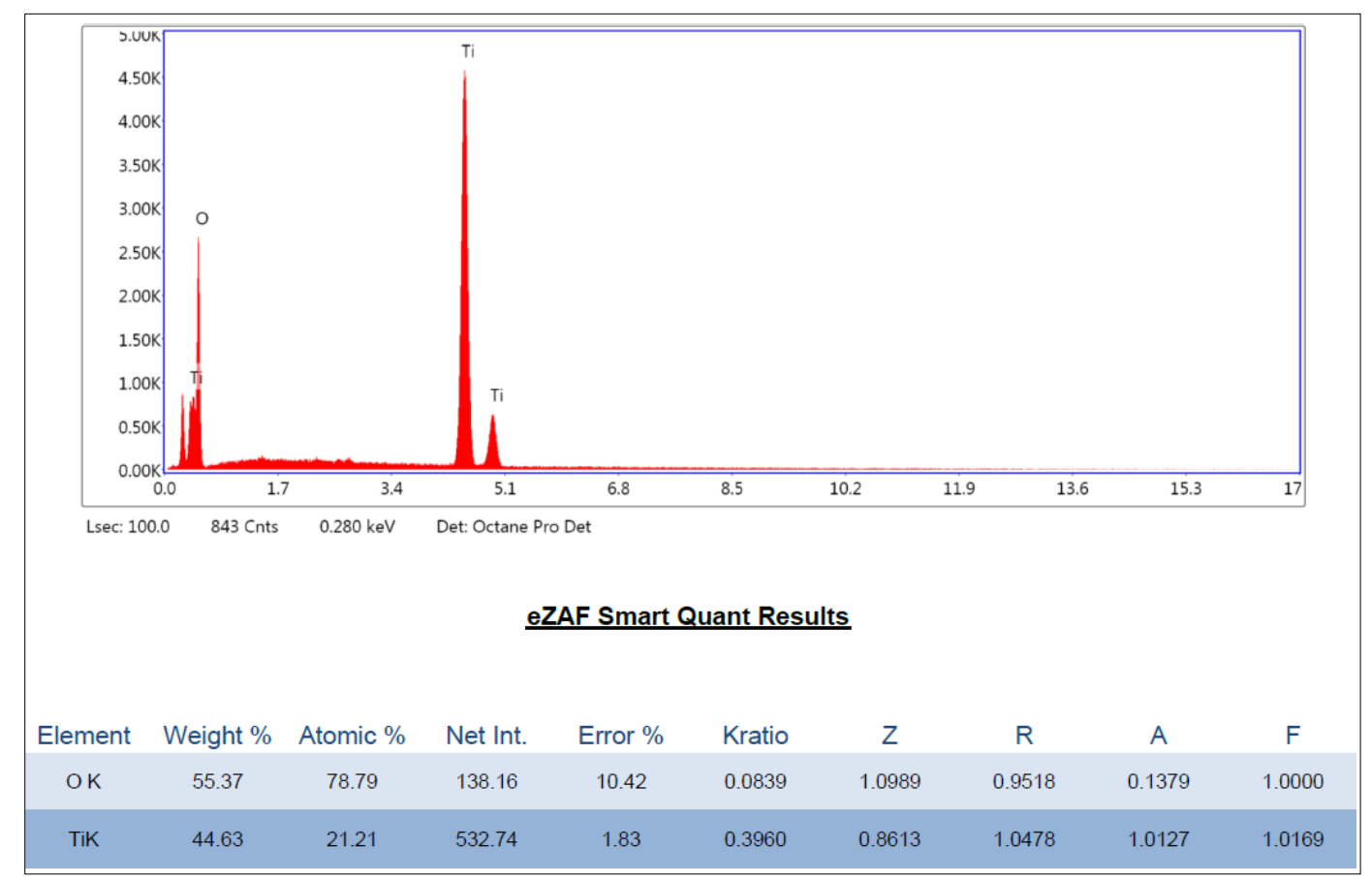

Şekil 5. $\mathrm{TiO}_{2}$ nanotübe ait EDS analiz sonuçları 
24 saat $\mathrm{HCl}$ içerisinde bekletildikten sonra kalsine edilen $\mathrm{TiO}_{2}$ nanotüplerine ait XRD (Bruker D8 Advance Twin-Twin, Karlsruhe, Almanya) analizleri incelendiğinde $2 \Theta=$ $24.8^{\circ}, 48.7^{\circ}$ ve $39^{\circ}$ 'de ve $62.8^{\circ}$ 'de gözlenen pikler anataz yapıdaki $\mathrm{TiO}_{2}$ nanotüp formuna ait karakteristik piklerdir (Şekil 6) [34].

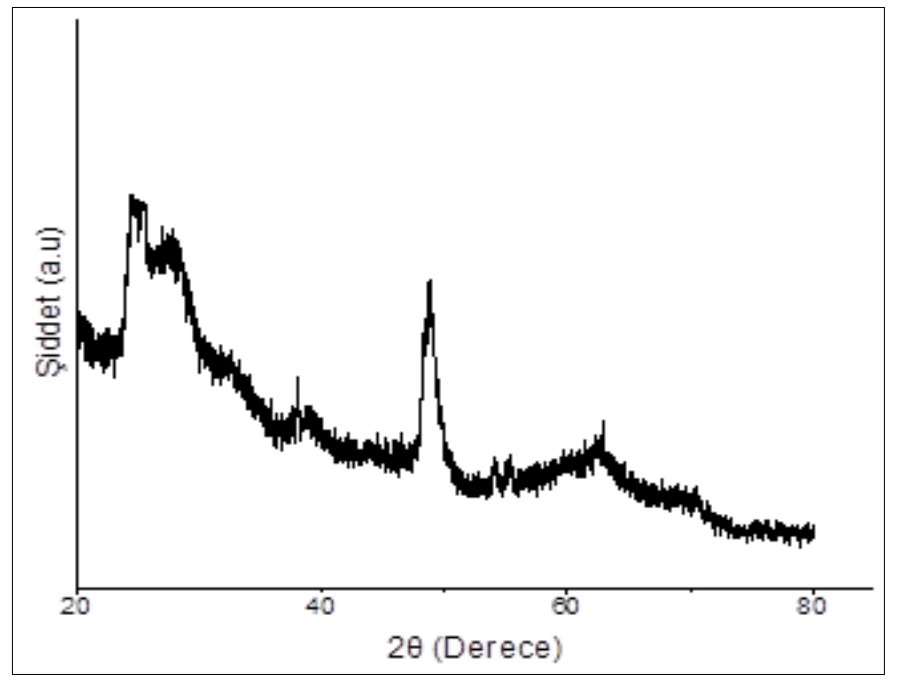

Şekil 6. $\mathrm{TiO}_{2}$ nanotübe ait XRD görüntüsü

\subsection{Fonksiyonlaştırılmış $\mathrm{TiO}_{2}$ Nanotüplerine ait SEM/EDS ve FTIR Analizleri}

Nanotüplerin metakrilik asit ile fonksiyonlaştırma işleminden sonra SEM görüntülerinde; merkezinde içi boş oyuk bulunan, uzun silindir şekilli, uzamış tübüler yapıların sayısının arttığı ve ağ yapısının belirginleştiği görüntülendi (Şekil 7a,b). Tübüler yapıların çapları 41.09-72.49 $\mathrm{nm}$ arasında ölçüldü (Şekil 7b).

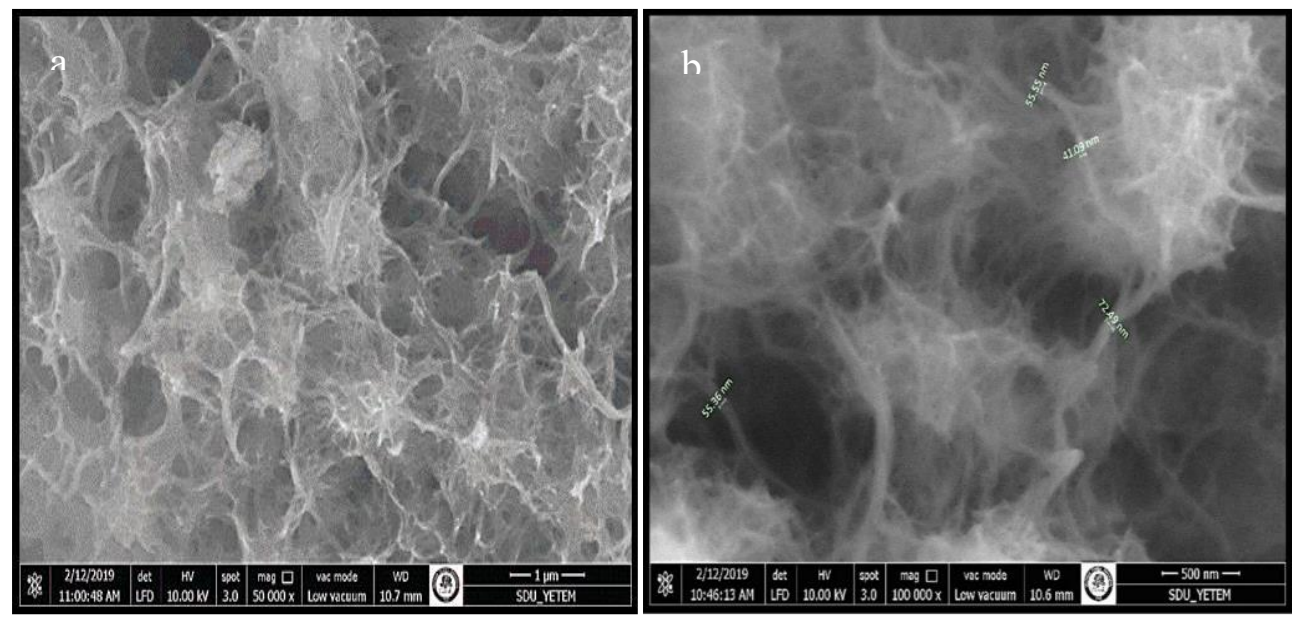

Şekil 7. Fonksiyonlaştırılmış $\mathrm{TiO}_{2}$ nanotübe ait örneğin yüzey morfolojisinin SEM görüntüleri,

a) $X 50.000$ büyütme b) X 100.000 büyütme

Metakrilik asit kullanılarak yapılan fonksiyonlaştırma sonrası EDS analizi sonucunda, titanyum ve oksijen'in yanısıra düşük miktarda karbon yüzdesi elde edildi (Şekil 8). 


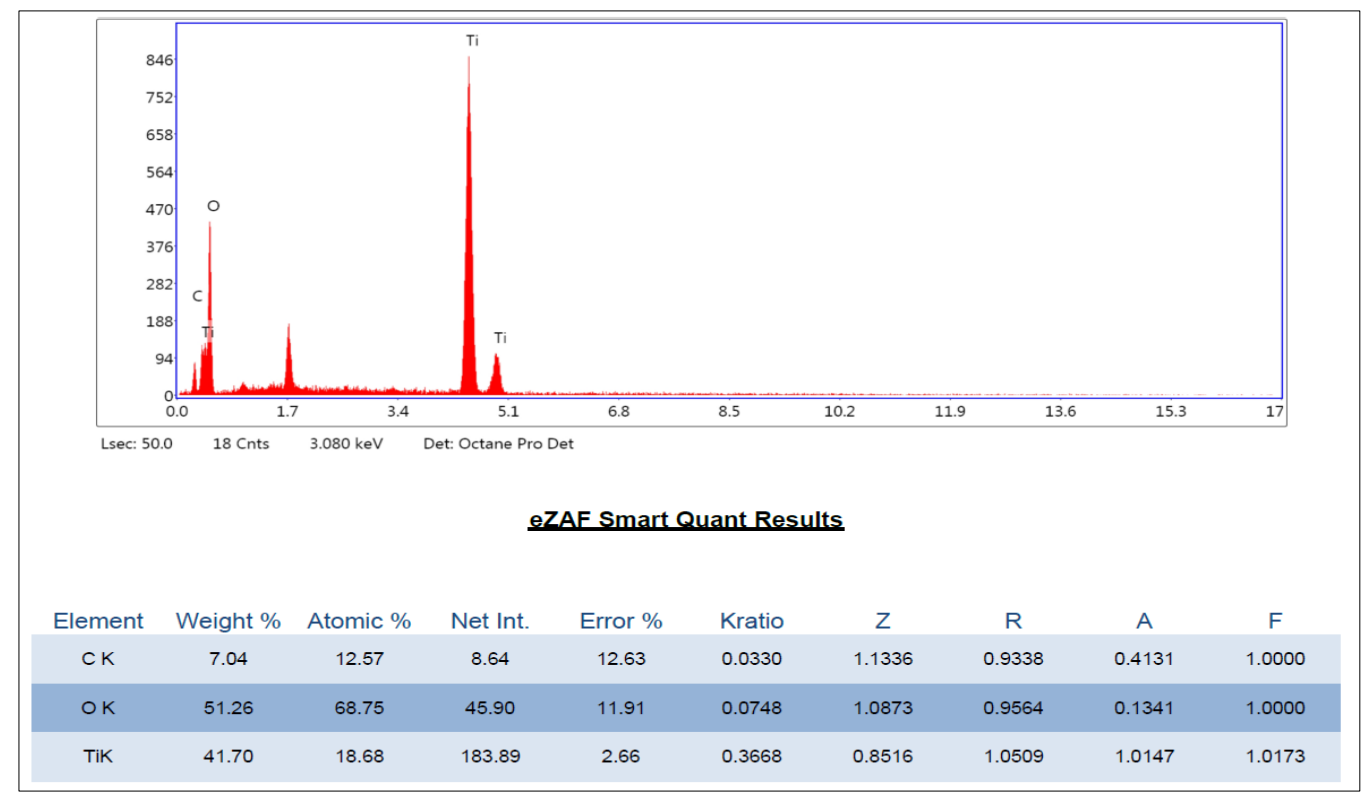

Şekil 8. Fonksiyonlaştırılmış $\mathrm{TiO}_{2}$ nanotübe ait EDS analiz sonuçları

Fonksiyonlaştrılmış $\mathrm{TiO}_{2}$ nanotüplerine ait FTIR (Perkin Elmer Spectrum BX, Waltham, MA 02451, ABD) spektrumunda 1542, 1459 ve $1401 \mathrm{~cm}^{-1}$ dalga boylarında titanyum ile metakrilik asitin $\left(\mathrm{C}_{4} \mathrm{H}_{6} \mathrm{O}_{12}\right)$ karboksilik grubu arasında güçlü pikler görüldü [35]. Metakrilik asit ile $\mathrm{TiO}_{2}$ arasındaki bağlanmadan kaynaklı $1636 \mathrm{~cm}^{-1}$ dalga boyundaki $\mathrm{C}=\mathrm{C}$ vinil bandlarının varlığı metakrilik asidin $\mathrm{TiO}_{2}$ nanotüpler ile başarılı bir şekilde bağlandığını gösterdi (Şekil 9) [36].

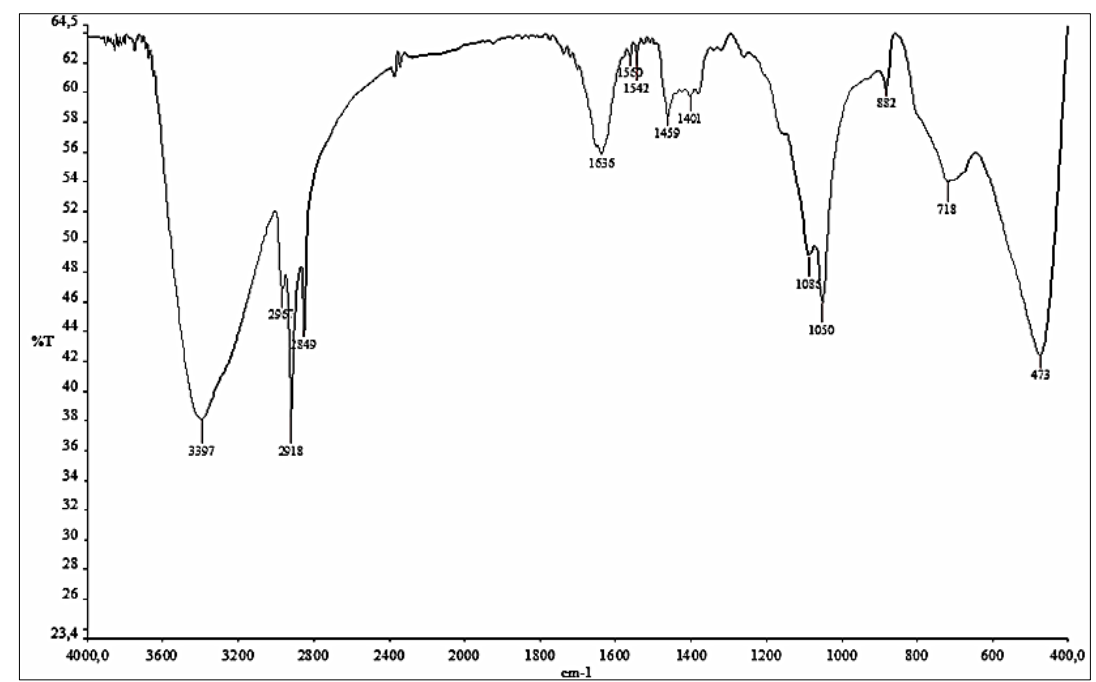

Şekil 9. Fonksiyonlaştırılmış $\mathrm{TiO}_{2}$ nanotübe ait FTIR spektrumu

\section{Sonuç ve Yorum}

Uygulanan hidrotermal sentezde toz formdaki $\mathrm{TiO}_{2}$ 'nin, $\mathrm{TiO}_{2}$ nanotüpe dönüşümünde ilk olarak, $\mathrm{NaOH}$ çözeltisi içerisinde $\mathrm{TiO}_{2}$ 'deki Ti-O-Ti bağları kırılarak, sodyum titanat $\left(\mathrm{Na}_{2} \mathrm{Ti}_{3} \mathrm{O}_{7}\right)$ nanotabakaları oluşturuldu. Daha sonra $\mathrm{Na}_{2} \mathrm{Ti}_{3} \mathrm{O}_{7}$, hidroklorik asit $(\mathrm{HCl})$ kullanılarak iyon değişimi ile hidrojen titanata $\left(\mathrm{H}_{2} \mathrm{Ti}_{3} \mathrm{O}_{7}\right)$ dönüştürülürken yapının da tübüler forma dönüştüğü görüldü. Bu aşamada sadece asit ile yıkamanın tübüler formun oluşumu için yeterli olmadığı gözlenmiştir. 
Son olarak, $\mathrm{H}_{2} \mathrm{Ti}_{3} \mathrm{O}_{7}$, anataz yapıdaki $\mathrm{TiO}_{2}$ nanotüpleri oluşturmak için kalsine edildi. Sentezi gerçekleştirilip kurutulan $\mathrm{TiO}_{2}$ nanotüplerin metakrilik asit ile yüzey modifikasyon işlemi uygulanarak, fonksiyonlaştırılmış $\mathrm{TiO}_{2}$ nanotüp sentezi gerçekleştirilmiştir. Fonksiyonlaştırılmış grupların band aralıkları FTIR ile analiz edilmiştir.

$\mathrm{TiO}_{2}$ tozunun yapısı, hidrotermal koşullar, hidrotermal reaksiyondan sonra yapıdaki safsızlık iyonlarını gidermek için yapılan yıkama aşaması ve en önemlisi uygulanan asidin derişimi, uygulama süresi ile etkileşim şekli nanotüp yapısını ve fiziksel-kimyasal özelliklerini belirlemede önemli bir rol aldığı gözlemlendi.

Çalışmamız yüksek maliyetine ilaveten yüksek safsızlık oranına sahip nanotüplerin sentez koşullarını optimize etmek amacıyla gerçekleştirilmiştir. Teknolojinin ilerlemesiyle birlikte inorganik nano yapıya sahip materyaller, farklı bilim dalları arasında yeni bir ilgi alanı oluşturmuştur. Toz formda bulunan nanomalzemelerin farklı formları ile ilgili yüksek maliyet ve içerdikleri safsızlıklar sebebi ile yeterli ilerleme sağlanamamıştır.

Literatür çalışmalarında belirtilen tüm koşullarda nanotüplerin oluştuğu yönünde sonuçlar verilirken, karakterizasyon sonuçlarının nanomalzemenin toz yapısına ait olduğu, tübüler yapılara ait formların oluşumunu gösteren karakterizasyon görüntülerine rastlanılmamaktadır. Dolayısıyla hem doğru formda nanotüp yapısı hem de istenilen saflıkta titanyum dioksit yapılarının eldesi ve deney koşullarının optimize edilmesi ile sentezlenen fonksiyonlaştırılmış $\mathrm{TiO}_{2}$ nanotüp çalışması ile literatüre doğru bilgi şeklinde katkı sağlayacağını düşünmekteyiz.

\section{Araştırmacıların Katkı Oranı Beyanı}

Banu ESENCAN TÜRKASLAN: Proje Yönetimi, Araştırma, Orijinal Taslak Yazımı, Kaynak/Materyal/Malzeme Temini, Denetim/Gözlem/Tavsiye.

Melek AKTAŞ: Araştırma, Doğrulama, İnceleme ve Düzenleme.

Sultan AKAR:, Araştırma, Doğrulama, İnceleme ve Düzenleme.

\section{Destek ve Teşekkür Beyanı}

$\mathrm{Bu}$ çalışmanın yazarları olarak herhangi bir destek ve teşekkür beyanımız bulunmadığını bildiririz.

\section{Çatışma Beyanı}

$\mathrm{Bu}$ çalışmanın yazarları olarak herhangi bir çatışma beyanımız bulunmadığını bildiririz.

\section{Etik Kurul Onayı ve/veya Aydınlatılmış Onam Bilgileri}

Bu çalışmanın yazarları olarak herhangi bir etik kurul onayı ve/veya aydınlatılmış onam bilgileri beyanımız bulunmadı̆̆ını bildiririz.

\section{Kaynakça}

[1] M. Naquib, Y. Gogotsi, "Synthesis of two-dimensional materials by selective extraction," Acc. Chem. Res., 48(4), 128-135, 2014.

[2] T. Öztürk, "Production and characterization of $\mathrm{TiO}_{2}$ nanotubes on CP titanium surface," M.S. thesis, Dept. Mater. Eng., Istanbul Univ., Istanbul, Turkey, 2012.

[3] K. Jukk, N. Kongi, "Electrochemical oxygen reduction behaviour of platinum nanoparticles supported on multi-walled carbon nanotube/titanium dioxide composites," J. Electroanal. Chem., 735, 68-76, 2014.

[4] K. Hashimoto, H. Irie, and A. Fujishima, " $\mathrm{TiO}_{2}$ photocatalysis: A historical overview and future prospects," Jpn. Appl. Phys., 44(12), 8269-8285, 2005. 
[5] A. L. Linsebigler, G. Lu, and J. T. Yates, "Photocatalysis on $\mathrm{TiO}_{2}$ surfaces: Principles, mechanisms, and select result," Chem. Rev., 95(3), 735-758, 1995.

[6] J. M. Macak, H. Tsuchiya, A. Ghicov, K. Yasuda, R. Hahn, S. Bauer, and P. Schmuki, "TiO nanotubes: Self-organized electrochemical formation, properties and applications," Curr. Opin. Solid State Mater. Sci., 11(1-2), 3-18, 2007.

[7] U. Diebold, "The surface science of titanium dioxide," Surf. Sci. Rep., 48(5-8), 53-229, 2003.

[8] A. Hagfeldt, M. Graetzel, "Light-induced redox reactions in nanocrystalline systems," Chem. Rev., 95(1), 49-68, 1995.

[9] A. Mills, S. Le Hunte, "An overview of semiconductor photocatalysis," J. Photochem. Photobiol. A Chem., 108(1), 1-35, 1997.

[10] S. Eustis, M. A. El-Sayed, "Why gold nanoparticles are more precious than pretty gold: Noble metal surface plasmon resonance and its enhancement of the radiative and nonradiative properties of nanocrystals of different shapes," Chem. Soc. Rev., 35(3), 209-217, 2006.

[11] N.M Mohsen, R.G. Craig, "Effect of silanation of fillers on their dispersability by monomersystems," Jour. of Oral Rehabil., 22(3),183-89, 1995.

[12] X. Chen, S. S. Mao, "Titanium dioxide nanomaterials: Synthesis, properties, modifications and applications," Chem. Rev., 107(7), 2891-2959, 2007.

[13] D. V. Bavykin, J. M. Friedrich, and F. C. Walsh, "Protonated titanates and $\mathrm{TiO}_{2}$ nanostructured materials synthesis properties and applications," Adv. Mater., 18(21), 2807-2824, 2006.

[14] A. Ghicov, P. Schmuki, "Self-ordering electrochemistry: A review on growth and functionality of $\mathrm{TiO}_{2}$ nanotubes and other self-aligned MO(x) structures," Chem. Commun., 28(20), 2791-2808, 2009.

[15] M. S. Sander, M. J. Cote, W. Gu, B. M. Kile, and C. P. Tripp, "Template-assisted fabrication of dense, aligned arrays of titania nanotubes with well-controlled dimensions on substrates," Adv. Mater., 16(22), 2052-2057, 2004.

[16] D. Zhang, L. Qi, J. Ma, and H. Cheng, "Formation on crystalline nanosized titania in reverse micelles at room temperature," J. Mater. Chem., 12(12), 3677-3680, 2002.

[17] T. Kasuga, M. Hiramatsu,A. Hoson, T. Sekino, and K. Niihara, "Titania nanotubes prepared by chemical processing," Adv. Mater., 11(15), 1307-1311, 1999.

[18] G. H. Du, Q. Chen, R. C. Che, Z. Y. Yuan, and L. M. Peng, "Preparation and structure analysis of titanium oxide nanotubes," Appl. Phys. Lett., 79(22), 3702-3704, 2001.

[19] M. Adachi, Y. Murata, I. Okada, and S. Yoshikawa, "Formation of titania nanotubes and applications for dye-sensitized solar cells," J. Electrochem. Soc., 150(8), 488-493, 2003.

[20] H. H. Ou, S. L. Lo, "Review of titania nanotubes synthesized via the hydrothermal treatment: Fabrication, modification, and application," Sep. Purif. Technol., 58(1), 179-191, 2007.

[21] S. Uchida, R. Chiba, M. Tomiha, N. Masaki, and M. Shirai, "Hydrothermal synthesis of titania nanotube and its application for dye-sensitized solar cell," Stud. Surf. Sci. Catal., 70(6), 418, 2002.

[22] K. S. Raja, M. Misra, and K. Paramguru, "Formation of self-ordered nano-tubular structure of anodic oxide layer on titanium," Electrochim. Acta, 51(1),154-165, 2005.

[23] T. Kisumi, A. Tsujiko, K. Murakoshi, and Y. Nakato, "Crystal-face and illumination intensity dependences of the quantum efficiency of photoelectrochemical etching, in relation to those of water photooxidation, at $n-\mathrm{TiO}_{2}$ (rutile) semiconductor electrodes," J. Electroanal. Chem., 545, 99-107, 2003.

[24] J. Yu, H. Yu, "Facile synthesis and characterization of novel nanocomposites of titanate nanotubes and rutile nanocrystals, " Mater. Chem. Phys., 100(2-3), 507-512, 2006.

[25] N. Liu, X. Chen, J. Zhang, and J. W. Schwank, "A review on $\mathrm{TiO}_{2}$-based nanotubes synthesized via hydrothermal method: formation mechanism, structure modification, and photocatalytic applications," Catalysis Today, 225, 34-51, 2014.

[26] D. V. Bavykin, J. M. Friedrich, and F. C. Walsh, "Protonated titanates and $\mathrm{TiO}_{2}$ nanostructured materials: synthesis, properties, and applications," Adv. Mater., 18(21), 2807-2824, 2006.

[27] A. L. Papa, N. Millot, L. Saviot, R. Chassagnon, and O. Heintz, "Effect of reaction parameters on composition and morphology of titanate nanomaterials," J. Phys. Chem., 113(29), 12682-12689, 2009.

[28] M. Inagaki, N. Kondo, R. Nonaka, E. Ito, M. Toyoda, K. Sogabe, and T. Tsumura, "Structure and photoactivity of titania derived from nanotubes and nanofibers," J. Hazard Mater., 161(2-3), 15141521, 2009.

[29] W. Zhou, H. Liu, R.I. Boughton, G. Du, J. Lin, J. Wang, and D. Liu, "One-dimensional singlecrystalline Ti-O based nanostructures: Properties, synthesis, modifications and applications," J. Mater. Chem., 20(29), 5993-6008, 2010.

[30] Z. Y. Yuan, B. L. Su, "Titanium oxide nanotubes, nanofibers and nanowires," Colloids Surfaces A Physicochem. Eng. Asp., 241(1-3),173-183, 2004. 
[31] S. Thennarasu, K. Rajasekar, and K. Balkis Ameen, "Hydrothermal temperature as a morphological control factor: preparation, characterization and photocatalytic activity of titanate nanotubes and nanoribbons," J. Mol. Struct., 1049, 446-457, 2013.

[32] N. Keklikcioğlu Çakmak, G. Topal Canbaz, " $\mathrm{TiO}_{2}$ Nanopartikülü ve $\mathrm{TiO}_{2} /$ Aktif Çamur Sentezi ile Sulu Çözeltiden Cu (II) İyonlarının Adsorpsiyonu,” Gümüşhane Fen Bil. Ens. Der., 10(1), 86-98, 2020.

[33] T. H. T. Vu, H. T. Au, L. T. Tran, T. M. T. Nguyen, T. T. T. Tran, M. T. Pham, M. H. Do, and D. L. Nguyen, "Synthesis of titanium dioxide nanotubes via one-step dynamic hydrothermal process," $J$. Mater. Sci., 49(16), 5617-5625, 2014.

[34] L. Cui, K. N. Hui, K. S. Hui, S. K. Lee, W. Zhou, Z. P. Wan, "Facile microwave-assisted hydrothermal synthesis of $\mathrm{TiO}_{2}$ nanotubes," Mater. Lett., 75, 175-178, 2012.

[35] S.M.Z. Khaled, R. J. Miron, D. W. Hamilton,P. A. Charpentier, A. S. Rizkalla, "Reinforcement of resin based cement with titania nanotubes,"Dental Mat., 26, 169-178, 2010.

[36] K. Goto, J. Tamura, S. Shinzato, S. Fujibayashi, M. Hashimoto, M. Kawashita, T. Kokubo, T.Nakamura, "Bioactive bone cements containing nano-sized titania particles for use as bone substitutes, "Biomaterials, 26 (33),6496-505, 2005. 